\title{
Mobile phone use in two secondary schools in Tanzania
}

\author{
Andrew Joyce-Gibbons ${ }^{1} \cdot$ David Galloway ${ }^{1}$. \\ Andrew Mollel ${ }^{2} \cdot$ Sylvester Mgoma $^{3}$. \\ Madeleke Pima $^{2} \cdot$ Enos Deogratias ${ }^{3}$
}

Received: 8 November 2016 / Accepted: 3 February 2017 / Published online: 23 February 2017

C The Author(s) 2017. This article is published with open access at Springerlink.com

\begin{abstract}
Mobile phone technology in Tanzania has grown rapidly but there is insufficient data on its application in schools. This paper aims to show how students in the first and third year (F1 and F3) teachers in two rural secondary schools perceived its use. F1 and F3 students completed a questionnaire. Teachers and students in F1 and F3 discussed the uses and misuses of mobile phones in separate focus groups. Although they served similar areas the two schools differed in students' use - and awareness of misuse - of mobile phones. Most students had access to a mobile phone, but were not permitted to bring them to school. Few teachers could see a positive use for the technology in the curriculum. There is an urgent need for pedagogical resources to support the introduction of mobile technology into classrooms but equally it is crucial that any such introduction is through a process of engagement with the concerns of students, teachers and the wider community with frank discussion about both the dangers and the potential benefits of using mobile phones in learning.
\end{abstract}

Keywords Mobile technology Student learning $\cdot$ Teacher perceptions $\cdot$ Barriers $\cdot$ BYOD

\section{Introduction}

Mobile phone use in Tanzania has been growing rapidly in Tanzania in the past decade (Kafyulilo 2014) with ownership in the general population in 2015 running at $64 \%$ $(31,900,000$ users); this is compared to the $1 \%$ of the population with fixed telephone lines (150,000 users) (Kihwele and Bali 2013; Central Intelligence Agency 2017).

Andrew Joyce-Gibbons

andrew.joyce-gibbons@durham.ac.uk

1 Durham University, Durham City, County Durham, UK

2 Sebastian Kolowa Memorial University, Lushoto, Tanga, Tanzania

3 St Rock College of Early Education, Korogwe, Tanga, Tanzania 
Handset prices have plummeted and studies across a range of African countries suggest that even in remote rural areas, young people have access to a mobile phone, even if they do not own it themselves. An increasing number of these phones are smart phones, particularly in urban centres (Swarts and Wachira 2010; Porter et al. 2016). This creates obvious possibilities for their use in education.

Lack of adequate traditional landline communication infrastructures is 'pushing' policy makers and educators to consider using mobile phones in learning (Kafyulilo 2014). Charging mobile phones depends only on occasional electricity supply, something increasingly possible with solar power, rather than the large and constant supply required for computers. More positively, learning by mobile phone can be personal, unobtrusive and spontaneous (Traxler and Kukulska-Julme 2005). Other key 'pull' factors include portability, affordability, accessibility, operability and applicability (Kafyulilo 2014). Nevertheless, although these are necessary they are not sufficient. A key requirement is sustainability.

For technology to be meaningfully deployed in Tanzanian schools it must be sustainable. If it is not, then a failure in the equipment will all too easily lead to a failure in the learning which the technology was designed to support. The criteria which technology must meet for sustainable deployment in the classroom are: i) low energy requirements; ii) long life-cycle; iii) minimum maintenance; iv) easy repair (Zlotnikova and van der Weide 2015). These are also the specifications for environmentally sustainable Green IT (Murugesan 2008).

\subsection{Mobile devices in education}

Although mobile phones meet these criteria very well, other e-technologies can also do so. There has been a successful long-running project in Tanzania using E-Readers to deliver text book and other reading materials in primary schools. The project researched the introduction of e-readers into two rural primary schools, working with four teachers in the first school (where the ratio of e-readers to pupils was 1:2), seven in the second (the ratio of e-readers to pupils was 1:3). The results from the pilot data indicated that ereaders were a successful means of giving access to greater resources for learners in remote rural areas. There were also gains in student attendance and some evidence of improved attainment (Machuve et al. 2014).

Despite the potential benefits and the clear appeal of mobile phones in society at large in Tanzania, educational providers have barely tapped the possibilities presented by this technology (Swarts and Wachira 2010). Kihwele and Bali (2013) identified deep suspicion among teachers and parents in Dodoma about the risks of allowing learners to access mobile phones. They believed that it had a detrimental effect on the performance and moral values, not only for the learner who owned the mobile but also for their friends who might borrow or share it.

Some projects in Tanzania, notably the BridgeIT project ('Elimu kwa Teknolojia') have explored the use of mobile phones in teaching and learning. In this project, teachers downloaded videos on Mathematics, Science and HIV/AIDS education and watched them with students as part of their regular school lessons. Positive effects were reported on student motivation as well as reduced teacher planning and preparation time. Teachers also reported that it helped alleviate the problem of over-crowding in classrooms (Kasumuni 2011). Whilst impressive and long running, (parents voluntarily 
donated TS2000 per month to contribute to electricity costs,) the BridgeIT project did not give students the opportunity to access resources via mobile phones for themselves. Despite encouraging results in some areas, there remains a shortage of evaluated mobile learning projects in Tanzania (Machuve et al. 2014).

\subsection{Bring your own device}

The increasing access to mobile phones among young people has led to an increase in using learner's own devices in lessons. Bring Your Own Device (BYOD) lessons have gained in popularity across the world (Jones et al. 2014; Traxler 2016). BYOD holds several attractions for schools and HEIs. Firstly, it allows learners to access online learning resources which would be unavailable without significant infrastructural and capital investment by the institution. Secondly it allows learning which is more closely aligned with learner interests, expectations and lifestyle in the rest of their society (Cheng et al. 2016; Gillies 2016).

Particularly in the context of sub-Saharan Africa the ability to use mobile technology to compensate for a lack of existing infrastructure, erratic internet connection and unreliable power supply are all strong 'push' factors towards the adoption of a BYOD model. There are also significant 'pull' factors as well. Kamau (2014) found that learners enjoyed the opportunity to record lessons and reflect on them later. Teachers also used mobile phones to access learning materials to support their preparation.

These pull and push factors have combined to make mobile learning and the BYOD model increasingly popular. Mtebe and Kissaka (2015) found that $48 \%$ HEIs in Africa relied on mobile devices to support blended learning in some of their courses. The University of Dar Es Salaam (UDSM) runs three post graduate courses on a blended learning model.

Successful introduction of BYOD learning requires not only hardware but a recognition that the technology changes how the learners will approach learning. Researchers argue forcefully for a commensurate change in the approach to teaching and learning at a policy and a practical level. Lessons should become less teacher-centric and learners empowered to determine how and for what purpose they use their devices. Teachers must be given support so that an increase in technology is not a challenge to their competency as teachers. Such support must be both technical and pedagogical (Cheng et al. 2016). The age of a teacher and their sense of self efficacy towards the use of technology can be predictors of teacher adoption of a BYOD approach (Dennen and Hao 2014; Song and Kong 2017). BYOD learning lends itself less to didactic, rigid teaching and more to a collaborative, socio-constructivist approach. However to implement this requires a radical re-alignment of institutional and classroom culture by teachers and management (Cochrane et al. 2014). This step is not to be taken lightly given that BYOD initiatives have several inherent challenges that must be specifically addressed if they are to succeed.

The first has been identified as a major barrier to widespread uptake in a number of sub-Saharan African countries. Levels of mobile phone ownership vary widely among different socio-economic groups and ages. Whilst it might be possible for learners to access mobiles informally, that does not mean they will be able to bring them to school or use them regularly for school work. Therefore BYOD is seldom encouraged in 
school systems (Porter et al. 2016). Whilst the issue of equity is a receding problem in the developed world, there are still social pressures for learners to be up-to-date with the latest technology (Dennen and Hao 2014).

Parental engagement was shown to be a key factor in the support of BYOD lessons in Virginian schools, with level of parental education, age of the learner and level of technology available in the home all found to be predictors of parental attitudes to BYOD (Kiger and Herro 2015). Adhikari et al. (2016) found that BYOD lessons could actually increase parental feelings of isolation from their children's work as they felt excluded by the personal nature of the device and their lack of familiarity with the apps being used. Both sets of researchers argue that successful BYOD lessons require deliberate engagement of parents in the planning and introduction process before the devices are used in the classroom.

In addition there are technical challenges to be overcome, as many learning resources are not optimised for mobile platforms. Small screen-size and low memory can also be inhibiting factors to both classroom use and learning in informal contexts (Khaddage et al. 2016). Practically learners also report that having mobile devices in class can result in greater distraction for them and teachers also report taking extra time to have to monitor behaviour (Adhikari et al. 2016; Kumar 2016). Learning using mobile phones in ways which bridge the formal and informal learning contexts clearly has huge potential, however, the research is unclear whether relying on learners to bring their own devices to the classroom is the best way to take advantage of the benefits offered by mobile technology.

\subsection{Teacher and pupil attitudes to mobile phones}

This dearth in mobile learning technology research can be explained in large part by the suspicion with which mobile phones in the hands of students are regarded by teachers. In a study covering teachers and pre-service teachers from Dar es Salaam University College of Education and students from one secondary school, also in Dar es Salaam, Kafyulilo (2014) reported that teachers were more alarmed at the potentially negative aspects of mobile phone use than they were attracted by the benefits of using them. Key fears include: distraction from study by social messaging and the viewing of pornography.

Both of these fears are well supported by current research. Use of social media is widespread among adolescents in many African countries and use has far outstripped the development of strategies for disseminating safe-use messages (UNICEF/ Intermedia 2013). Pornography is also widespread and increasingly disseminated through smart phones (Porter et al. 2016). Therefore concerns about increasing the use of mobile phones in schools are commonplace in, not only in Tanzania but in South Africa (Ford and Batchelor 2007) and Ghana (Grimus and Ebner 2014).

\subsection{Cyberbullying}

Cyberbullying has been recognised as a growing problem globally for over a decade (Ovejero et al. 2016). Burton and Leoschut (2013) reported that 20.9\% of the South African students participating in their study had experienced some form of cyberbullying or online violence. This figure appears to be growing rapidly. Porter et al. 
(2016, p.31) found that in Ghana $16.3 \%$ had experienced unwanted, unpleasant or upsetting calls or texts. In Malawi this figures was $27.6 \%$ and in South Africa $55 \%$. Whilst there is a desire among adolescents to learn more about e-safety, they frequently lack knowledge of reliable sources of information which they can access (UNICEF/ Intermedia 2013).

Increasing use of mobile phones in the classroom can pose a danger to students' education from their misuse by teachers. Disruption occurs when teachers receive calls during lessons. Frequently these are from customers of side-businesses run by teachers seeking to supplement their erratically paid salary. Students can also feel threatened by teachers sending sexually harassing text messages or making sexual advances in phone calls (Porter et al. 2016).

\subsection{Tanzania Government policy on mobile phones in schools}

Despite widespread concerns about the place of mobile phones in secondary school learning, the government of Tanzania is committed to developing their use as part of a strategy to enable schools to deliver a higher quality of education. Mobile phone technology has been repeatedly recognised as a potentially important channel for diversifying education to increase the competitiveness in the Tanzanian workforce in an increasingly globalized future (United Republic of Tanzania 1999; Ministry of Education and Vocational Training 2007; Ministry of Education and Vocational Training 2010). However, this recognition of their importance has not moved past general broad statements of support. The problem of how to deal with mobile phone use remains one to be resolved at a local level as elsewhere in Africa (Porter et al. 2016).

\subsection{Research questions}

Little is known about the ages at which students start to use mobile phones, or about sex differences in their use. The same applies to the practical possibilities for using mobile phone technology in schools. The research questions are therefore:

- What are the patterns of mobile phone use among students in rural Tanzanian secondary schools?

- Do differences exist between patterns of mobile phone use in rural Tanzanian secondary schools depending on age/form or gender?

- How do teachers and students perceive mobile phone use in relation to learning in rural Tanzanian secondary schools?

\section{Method}

\subsection{Questionnaire design}

Students in two rural secondary schools in northeast Tanzania completed a short exploratory questionnaire on their experiences using mobile phones $(N=252)$. Respondents were drawn from Form 1 (usually 11-12 years old) and Form 3 (usually 13-14 years old). However due to discrepancies in record keeping by schools and 
families, repetition of years by some students and pauses in education due to family or economic commitments, there was some variation in the age of pupils in each Form. The data were collected as part of a larger study looking at the challenges secondary school students faced in transition between primary and secondary schools. Questions were asked about: i) the use of mobile phones; ii) the use of basic and/or smart phones; iv) the frequency of text messaging; v) phone ownership. An open-ended question was also asked relating to experiences of cyber-bullying. All items were written in English and Kiswahili but most students wrote replies to the open ended questions in Kiswahili. The results are presented as frequency tables and where appropriate the chi square test is used to compare groups, for example boys and girls.

Many items in the questionnaire were adapted from other instruments used in research exploring bullying, truancy and learner attitudes (Galloway and Roland 2004). The items on mobile phone use were adapted from the recent study by Porter et al. (2016). In both of these cases, participants took the opportunity provided by privacy and anonymity to relate personal experiences without fear of repercussion. However, in both cases the questionnaire was necessary but not sufficient to access the necessary granularity of information. Focus groups made it possible to further explore attitudes to mobile phone use among teachers and young people.

\subsection{Focus groups}

Focus groups were also held with students in Form 1 and Form 3 in two secondary schools. Focus groups were also conducted with primary school Standard 6 pupils (1011 years old) in two primary schools in the same area. Student focus groups, both primary and secondary, comprised six pupils, three boys and three girls. Both schools were in rural areas in the north east of Tanzania. The student focus groups were asked to talk about whether they had used mobile phones and if so, how they used them outside schools. Teacher focus groups were conducted in the same primary and secondary schools. However, teacher participation was dependent on timetable and the good will of the head teacher. Therefore it was not possible to achieve a gender balance or consistent numbers of participants in each case. Additionally, researchers from our partner institutions in Tanzania advised us that it would not be appropriate to ask for teacher ages directly in the focus group setting. Therefore teacher ages are reported as estimates to within a decade alongside the results. Teacher groups were invited to describe their perceptions of current mobile phone use by students. They were then asked to consider the educational possibilities of using mobile phones in the classroom for learning and give their reactions. For student focus groups the questions and responses were translated between Kiswahili and English by the Research Associate attached to the project. Teacher focus groups were almost exclusively conducted in English with the Research Associate providing clarification on vocabulary where necessary.

\subsection{Ethical issues}

The project was supported by the local district local authority. Informed consent was sought in Kiswahili and English from staff and students by explaining the purpose of the project, and emphasizing that they were free not to answer any 
question and to withdraw at any point. They were also given an assurance that their school would not be named in any report or other publications arising from the project and that no individual student or teacher would be identified. With students these assurances were given in the presence of teachers but teachers were not present during the focus group sessions or the completion of the questionnaires.

\subsection{Schools}

The two participating secondary schools were similar in many respects. Both were in rural locations and both were part of the same administrative educational district. However, School 1 was situated more remotely, lying $6 \mathrm{~km}$ from the village it served with many children travelling from more remote locations, with journeys of $9 \mathrm{~km}$ not uncommon. School 2 was situated $1 \mathrm{~km}$ from the main village it served. Both schools showed evidence of serving settlements in similar socio-economic circumstances. For example, both schools had a more or less adequate number of desks and chairs for the classes visited; however, schools supplies and text books were clearly in short supply at both. Both schools reported high levels of truancy and drop out in the higher forms. The head teacher in School 1 was able to quantify this as approximately $40 \%$ in Form 3. In School 2 no figure was offered.

\section{Results}

\subsection{Exploring association between use of mobile phones and students' school, form and gender}

Table 1 shows that significantly more students attending School 1 reported using mobile phones than School 2. More Form 1 students reported using mobile phones than form 3 students. More male students reported having used them compared to female students.

Table 1 'Have you used a mobile phone?' by school, form and gender

\begin{tabular}{llllll}
\hline \multirow{4}{*}{ School } & & Yes & No & Total & Chi-square \\
& School 1 & 73 & 37 & 110 & {$\left[\chi^{2}(1)=5.64 ; \mathrm{p}=.02\right]$} \\
& School 2 & 66 & 63 & 129 & \\
Form & Total & 139 & 100 & 239 & \\
& Form 1 & 82 & 38 & 120 & {$\left[\chi^{2}(1)=10.25 ; \mathrm{p}<.01\right]$} \\
& Form 3 & 57 & 62 & 119 & \\
\multirow{3}{*}{ Gender } & Total & 139 & 100 & 239 & \\
& Male & 56 & 20 & 76 & {$\left[\chi^{2}(1)=6.32 ; \mathrm{p}=.01\right]$} \\
& Female & 57 & 46 & 103 & \\
& Total & 113 & 66 & 179 & \\
\hline
\end{tabular}




\subsection{Exploring association between use of basic or smart mobile phones and students' school, form and gender}

Chi-square tests were carried out to explore whether any statistically significant association existed between the use of basic or smart mobile phones by students and their school, form and gender. No statistically significant associations were shown to be present between the kind of mobile phones students used and their school $\left[\chi^{2}(1)=.07\right.$; $p=.79]$, form $\left[\chi^{2}(1)=2.80 ; p=.09\right]$ or gender $\left[\chi^{2}(1)=.283 ; p=.32\right]$.

\subsection{Exploring association between use of text message and students' school, form and gender}

Chi-square tests were carried out to explore whether any statistically significant association existed between student text messaging behaviour and their school, form and gender. Statistically significant associations were found to be present between the regularity with which students sent text messages and their school and their gender. The regularity with which a student sent text messages was associated with which school they attended and their gender. Table 2 shows the frequencies relating to these results. Students in School 1 were more frequent senders of text messages than those in School 2. No significant difference was found between Forms 1 and 3 in the frequency of sending texts. Male students reported texting more frequently each week than female students. More female students reported that they never sent any text messages than male students.

\subsection{Exploring association between experiences of cyber-bullying and students' school, form and gender}

Chi-square tests were carried out to explore whether any statistically significant association existed between student experiences of cyberbullying and their school, form and gender. Statistically significant associations were found to be present between

Table 2 'Have you ever sent a text message by mobile phone?' Frequencies by school, form and gender

\begin{tabular}{|c|c|c|c|c|c|c|c|}
\hline & & $\begin{array}{l}\text { Several times a } \\
\text { week }\end{array}$ & $\begin{array}{l}\text { Once a } \\
\text { week }\end{array}$ & $\begin{array}{l}\text { Now and } \\
\text { then }\end{array}$ & Never & Total & Chi-Square \\
\hline \multirow[t]{3}{*}{ School } & $\begin{array}{c}\text { School } \\
1\end{array}$ & 30 & 11 & 17 & 42 & 100 & $\begin{array}{c}{\left[\chi^{2}(3)=12.274\right.} \\
p=.01]\end{array}$ \\
\hline & $\begin{array}{l}\text { School } \\
2\end{array}$ & 17 & 28 & 22 & 64 & 131 & \\
\hline & Total & 47 & 39 & 39 & 106 & 231 & \\
\hline \multirow[t]{3}{*}{ Form } & Form 1 & 23 & 16 & 17 & 57 & 113 & {$\left[\chi^{2}(3)=2.415 ; p=.49\right]$} \\
\hline & Form 3 & 24 & 23 & 22 & 49 & 118 & \\
\hline & Total & 47 & 39 & 39 & 106 & 231 & \\
\hline \multirow[t]{3}{*}{ Gender } & Male & 24 & 7 & 16 & 26 & 73 & {$\left[\chi^{2}(3)=10.07 ; p=.02\right]$} \\
\hline & Female & 17 & 15 & 14 & 54 & 100 & \\
\hline & Total & 41 & 22 & 30 & 80 & 173 & \\
\hline
\end{tabular}


Table 3 'Have you been bullied in this way by other pupils?' Frequencies by school, form and gender

\begin{tabular}{llllll}
\hline \multirow{3}{*}{ School } & & Yes & No & Total & Chi-square \\
& School 1 & 15 & 96 & 111 & {$\left[\chi^{2}(1)=6.78 ; \mathrm{p}=.009\right]$} \\
& School 2 & 6 & 133 & 139 & \\
\multirow{5}{*}{ Form } & Total & 21 & 229 & 250 & \\
& Form 1 & 6 & 120 & 126 & {$\left[\chi^{2}(1)=4.37 ; \mathrm{p}=.03\right]$} \\
& Form 3 & 15 & 109 & 124 & \\
\multirow{3}{*}{ Gender } & Total & 21 & 229 & 250 & \\
& Male & 10 & 67 & 77 & {$\left[\chi^{2}(1)=1.65 ; \mathrm{p}=.15\right]$} \\
& Female & 8 & 101 & 109 & \\
& Total & 18 & 168 & 186 & \\
\hline
\end{tabular}

students' experiences of cyberbullying and the school they attended and the form they were in. Table 3 shows the frequencies relating to these results. More students reported experiencing some form of cyberbullying in school 1 compared to school 2. More students reported experiencing some form of cyberbullying in form 3 compared to form 1. There was no significant difference between boys and girls.

\subsection{Exploring association between awareness of cyber-bullying and students' school, form and gender}

Chi-square tests were carried out to explore whether any statistically significant association existed between student awareness of cyber-bullying taking place and their school, form and gender.

Statistically significant associations were found to be present between students' awareness of cyberbullying happening to others and the school they attended and the form they were in. Table 4 shows the frequencies relating to these results. More students were aware of cyber-bullying taking place in school 1 compared to school 2. More students were aware of cyber-bullying taking place in form 3 compared to form 1. As with Table 3, the results for gender were not significant.

Table 4 'Have you heard of it happening to other pupils?' Frequencies by school, form and gender

\begin{tabular}{llllll}
\hline \multirow{4}{*}{ School } & & Yes & No & Total & Chi-square \\
& School 1 & 57 & 54 & 111 & {$\left[\chi^{2}(1)=15.44 ; \mathrm{p}<.01\right]$} \\
& School 2 & 37 & 100 & 139 & \\
Form & Total & 94 & 154 & 250 & \\
& Form 1 & 38 & 87 & 126 & {$\left[\chi^{2}(1)=6.03 ; \mathrm{p}=.01\right]$} \\
& Form 3 & 56 & 67 & 124 & \\
\multirow{3}{*}{ Gender } & Total & 94 & 154 & 250 & \\
& Male & 35 & 42 & 77 & {$\left[\chi^{2}(1)=1.32 ; \mathrm{p}=.15\right]$} \\
& Female & 40 & 68 & 109 & \\
& Total & 75 & 110 & 186 & \\
\hline
\end{tabular}




\subsection{Exploring association between participation as cyber-bullies and students' school, form and gender}

Chi-square tests were carried out to explore whether any statistically significant association existed between student participation in cyber-bullying taking place and their school, form and gender. Statistically significant associations were found to be present between students being cyber-bullies and the school they attended and the form they were in. Table 5 shows the frequencies relating to these results. More students had participated in cyber-bullying in school 1 compared to school 2. More students had participated in cyber-bullying in form 3 compared to form 1. There was a nonsignificant tendency for boys to have participated more than girls.

\subsection{Open-ended question responses}

Students in School 1 were invited to elaborate on their responses to the questions related to cyberbullying: Q16) Have you been bullied this way by other pupils? Q17) Have you heard of it happening to other pupils? Q18) Have you bullied other pupils in this way? Their responses were translated from Kiswahili to English.

Of the 111 returned questionnaires, 15 contained responses which concerned firsthand experience of cyberbullying. Four were from Form one pupils ( 3 male and 1 female). Eleven were from Form 3 pupils ( 5 male and 6 female).

Table 6 contains the comments made by students in school 1 that relate to their experiences of cyberbullying. One mentions a social network (casual conversations with students and teachers showed that they were increasingly familiar with facebook but did not mention other social networks). Some students admitted that they had been victims of cyberbullying, others reported that they were aware that it happened to others.

Table 7 shows the responses of a further eight pupils, out of the 111 who returned questionnaires, who denied experience of cyberbullying. One was from Form 1 (Male) and seven were from Form 3 (3 male and 4 female). There were also additional ten responses which were simply negative: either 'No' or 'No I did not'.

Table 5 'Have you bullied anyone in this way?' Frequencies by school, form and gender

\begin{tabular}{llllll}
\hline \multirow{3}{*}{ School } & & Yes & No & Total & Chi-square result \\
& School 1 & 10 & 100 & 110 & {$\left[\chi^{2}(1)=5.83 ; \mathrm{p}=.02\right]$} \\
& School 2 & 3 & 134 & 137 & \\
Form & Total & 13 & 234 & 247 & \\
& Form 1 & 0 & 124 & 124 & {$\left[\chi^{2}(1)=13.83 ; \mathrm{p}<.01\right]$} \\
& Form 3 & 13 & 110 & 123 & \\
\multirow{3}{*}{ Gender } & Total & 13 & 234 & 247 & \\
& Male & 7 & 70 & 77 & {$\left[\chi^{2}(1)=3.38 ; \mathrm{p}=.07\right]$} \\
& Female & 3 & 103 & 109 & \\
& Total & 10 & 173 & 186 & \\
\hline
\end{tabular}


Table 6 Responses from students School 1 relating to experiences of cyberbullying by gender and form

\begin{tabular}{|c|c|c|}
\hline & Gender & Comment \\
\hline \multirow[t]{4}{*}{ Form 1} & Female & $\begin{array}{l}\text { I heard a student insulting another } \\
\text { student }\end{array}$ \\
\hline & Male & $\begin{array}{l}\text { Yes I have done that because they } \\
\text { are not cooperative }\end{array}$ \\
\hline & Male & Mistreated by embarrassing words \\
\hline & Male & $\begin{array}{l}\text { Yes I heard some girls starts to fight for } \\
\text { boys and put it in social media }\end{array}$ \\
\hline
\end{tabular}

Form 3 Female I've never been mistreated or mistreating others but I heard a person was mistreated

Female I never insult my fellow, I only heard it from another students

Female Through social network

Female I heard my fellow students were insulting through phone

Female Yes I was insulted

Female Yes I have seen it

Male I have been mistreated through message

Male I mistreated and mistreated too

Male Yes a little bit

Male [Female student] insulted me through message in the phone

Male Yes he was disturbing me a lot

\subsection{Teachers' views of mobile phone use from interviews}

One focus group of teachers was interviewed in each school. There were some common themes repeated regularly in teachers' general attitudes to mobile phones. There was no doubt among teachers in either school that some students, an increasing number, had access to mobile phones at home:

Table 7 Responses from students School 1 denying involvement in cyberbullying by gender and form

\begin{tabular}{lll}
\hline & Gender & Comment \\
Form 1 & Male & I have never been mistreated \\
Form 3 & Female & I've never mistreat anyone through phone \\
& Female & I've never send a message which mistreat \\
& anyone because I am respecting my self \\
& Female & No I haven't insult anyone through the phone \\
& Female & I have never been mistreated through this way \\
& Male & I have never done that because I don't have a phone \\
& Male & I have done it because I don't have a phone \\
& No I haven't mistreat anyone
\end{tabular}


School 1 teacher (Male, Approximately 35-45): Yeah, not most of them but a few of them, they do own a mobile phone. But not around the school campus. The do own it and when they come to school they try to hide it with their friends nearby school. And when they go back they take it and then they continue to get with their people who want to communicate. [...] For example, when the parents are, most of the parents especially those who are doing work far away from home they do, they just buy a mobile phone and they leave it at home. When the children get back from the school they try to communicate with their parents. But (they also) communicate with their boyfriends and girlfriends.

Teachers frequently referred to the misuse of mobile phones for what they saw as immoral purposes such as students flirting, looking at pornography or socialising through Whatsapp or Facebook when they should be studying. Teachers in both schools voiced frustration that the strong stance taken against the use of phones in schools was not backed up in the home life of students.

The economic situation of families was mentioned in both schools. Mobile phones were seen as positive, allowing parents working away to talk to their students, but also negatively as a threat to ongoing study as students used mobile phones to become more economically active.

School 2 Teacher (Male, Approximately 35-45): When we allow them it is fine but we are giving them freedom to communicate through mobile phones and giving them different materials but the problem is the issue of poverty. As we know, most of our students here, [...] are living with their grandparents. [...] And the grandparents are old men and women. And they are old enough, they can't work, they have no good income at all. Therefore, if you allow them to access phones, others will engage themselves in illegal business so they can get mobile phones. Girls might engage themselves in sexual business ... As you can see some of them are engaging themselves in illegal business [...] Some (have) relationship with some people who can use them sexually so that they can give them some money to afford some of their needs...And the boys are escaping from school and going to drive the motorcycles as a means of transport in town. So they can get money. So if we allow them to get this, to have those mobile phones, we are sending them to join those businesses.

Dissenting voices were rare but they did exist. Teachers in the focus groups showed great interest in anti-cyberbullying initiatives in the UK. In the course of discussion of these they would frequently admit a potential role for phones if they could be introduced in an appropriate way and their correct use adequately verified. One younger, male teacher (approximately 25-35 years old) took things further, actively embracing the potential offered by learning through mobile phones.

School 2 teacher (Male, Approximately 25-35): Using mobile phones in secondary school in according to the education regulation ... ministers [do] not allow a student to have mobile phones. However, I have a contrasting idea because I find that prohibiting the use of mobile phones has hindered educational advancement in secondary school because we can see now we have smartphone[s]... But I 
hope for myself that it would give some advantage to the student because it would be downloading a lot of materials. As far as we can see the shortage of teachers, especially in villages that there are a shortage of teachers and students have not got the appropriate materials. So if we allow them to use mobile phones maybe I hope that it would be something that [unintelligible] give them a sense of advancement.

The view that the government had banned the use of mobile phones in school was a widely held view, frequently expressed by teachers. This is despite several important policy documents which actively encourage the use of mobile phones as part of a broad ICT strategy. This teacher's position this proved to be provocative, with two colleagues disagreeing vigorously. The first of the dissenting voices (male, 35-45 years old) argued that the risk of legitimising mobile phone use was too great. Any possible educational benefits would be overwhelmed by the tacit encouragement to use social media inappropriately at home and in schools:

School 2 teacher (male, 35-45 years old): That might be a good idea, but I think that allowing students to use mobile phones might be a bigger problem. Because just imagine right now, we are not allowing them to use a mobile phone at school but they are texting them at home. Using mobile phones ... You might find they are chatting through different internet websites, like facebook and twitter, chatting with the friends instead of searching for educational materials [...] Another problem might be that during school hours you might find students chatting with their friends so I think that they can waste much time in chatting and doing other personal issues instead of studies through internet.

A second line of argument, reflected a common fixation on the need to engage with technology through the installation of new infrastructure in the form of computer suites. This would provide an avenue to allow students to engage constructively with the internet and with technology but in a controlled manner.

School 2 Teacher (female, 25-35): Maybe the government should have prepared themselves (by) preparing the schools. ...... We should have these computer labs so that the students, if really they want to search for these education matters in terms of international and what, they do have time (for) this.... (without, having cell phones).

The teacher who expressed a positive view of mobile phones responded, arguing that children had to be taught in a manner consistent with the world in which they were living. Mobile phones were also not to blame for unwanted pregnancy, student drop out or immoral activities - such things had been happening before the introduction of mobile phones:

School 2 Teacher: [...] If mobile phones were the source of pregnancy or the drop out of the students, so before the year 2000 there was pregnancy, maybe they can 
tell us what were the reasons then? ... But this is the world of science technology and we are teaching them, we are encouraging our students to learn science subjects including technology, and mobile phones are one of the products of technology. I think that we are the right people to educate the students because we are the tutors and therefore we have to teach them about how to have correct use of the mobile phone and not to prohibit them .... And we should not have these negative attitudes towards mobile phones. These young boys and girls are bright people, they have the right to learn through multi-media, the material from the internet. Another argument was that most of the children have got no financial ability to recharge their mobile phone so they can download materials; but you see they have taught us that they do download pornographs.... If there are students that are downloading pornographs, where do they get that money to recharge their mobile phones so they can accept those pornographs?

If mobile phones are to blame for undesirable behaviours, why did they happen for so long before mobile phones, the teacher asks. If price is a barrier to learning through phones, how can you be worried that students are able to download pornography? They are able to find funds from somewhere, why not for learning?

\subsection{Student discussion about their use of mobile phones}

Focus groups were conducted with Form 1 and Form 3 students in both schools. In general, students were reticent to talk about mobile phone use, even to admit that they ever used one. Form 1 students in School 2 were typical in their reluctance to admit mobile phone use:

Researcher 1: So, this question is about mobile phones, ok. So we know, remember we will not tell your teachers anything you tell us but have you ever used a mobile phone?

Mixed Voices: No.

Male student: Yes.

$[\ldots]$

Researcher 2: If your mother or father asked you to make a call to somebody, to a brother or sister or to somebody else in your family, could you do it?

Voices: Yes.

Researcher 2: Could you save a number on a mobile phone?

Voices: Yes.

Students were initially reluctant to admit the use of mobile phones immediately. However, when pressed would readily admit to being very familiar with the workings 
of a phone (suggesting that they had used them enough to gain familiarity with their processes). Those who were willing to say openly that they had used one only admitted to doing so outside schools, usually using one belonging to their parents. Only one group, Form 3 from School 2 admitted that some of them were familiar with cyberbullying.

Researcher 1: Have you ever heard of anybody sending text SMS messages which are bad or tell lies about people?

Research Associate: [Translating male student's reply] The answer is yes.

Researcher 1: Yeah? You've heard of this?

Research Associate: I would like to ask them which kind of SMS messages they are sending.

Researcher 1: Go on.

Research Associate: [Translating male student's reply] Sometimes they have been fighting with their friends.

Researcher 1: Right, ok.

Research Associate: When it will come, on that development, sometimes you can save a message for [unintelligible]... Sometimes they can send a message to warn if they are going to catch you and beat you.

School 1 Form 3 was the only student focus group to discuss the possible practical uses of mobile phones to support learning for young people.

Research Associate: What about good messages?

Research Associate: [Translating male student's reply] Sometime the message they send is we see study, we see subject. So they are using SMS for the case of study which subject.

Researcher 2: To ask another student for help.

M: Yes.

Research Associate: [Translating male student's reply] It is not full use but it is usually the price, the phone is used to the price, makes it difficult to pay.

Like the teachers, one of the students raises the issue of the price of mobile phones as a potential barrier to using them more in support of their learning. 


\section{Discussion}

The possible implications of the findings from this study will discussed in four sections corresponding to each of the three research questions and to the growing tendency towards BYOD classrooms.

\subsection{Patterns of mobile phone use among students in rural Tanzanian secondary schools}

The findings of this study build upon the previous work of Kafyulilo (2014) and Porter et al. (2012, 2016). Mobile phones are an aspect of everyday life that are very familiar to almost all children. The great majority have used them, whether they have regular access to them or not. They are aware of the concerns of adults about their use but are nonetheless attracted to them as a form of communication. Teachers in both schools reported that despite blanket official bans in school, learners were regularly caught with mobile phones, a finding which echoes experiences reported by teachers in Dodoma by Kihwele and Bali (2013) This would appear to be part of the more global trend towards mobile use and ownership. However, rates of uptake of smart phones were low in these schools; most pupils reported that if they had used a phone it was a basic one.

\subsection{Do differences exist between patterns of mobile phone use in rural Tanzanian secondary schools depending on age/form or gender?}

Mobile phone use - and misuse - was more prevalent in School 1 than School 2. More students admitted to having used a mobile phone, to have sent text messages, to be aware of cyberbullying and to have been involved in it. Unsurprisingly, more students in Form 3 admitted to awareness of cyberbullying than in Form 1. This appears inconsistent with the evidence in Table 1 that more Form 1 students admitted to having used a mobile phone. The most probable explanation is that Form 3 students were more aware of the blanket ban on mobile phones and penalties for using them in school, and saw denial as the safest response. A large scale study of young people and mobile phones in sub-Saharan Africa attempted to compensate for this reticence to trust the anonymity of the questionnaire and of focus groups by including other data collection methods including thematic story based interviews and interviews based on mobile phone call registers. Key to their success was the use of trained participant-researchers (Porter et al. 2016), a strategy the researchers in this study will adopt for future work in the area.

The subsequent open-ended questions may have elicited more considered responses because students interpreted them as asking less directly about an important school rule. The analyses by gender were consistent, with more boys admitting to using mobile phones than girls and to sending text messages. These results are inconsistent with reported mobile phone use by young people in South Africa and Ghana but consistent with reported use in Malawi (Porter et al. 2012). The difference between the two schools require further investigation. They are unlikely to be attributable to demographic factors as both schools served rural areas in north east Tanzania.

The increase in awareness of cyberbullying in Form 3 compared with Form 1 suggests the need for school-based programmes to teach responsible use of mobile 
phones. This is consistent with the findings of Porter et al. 2016; Kafyulilo 2014 and Burton and Leoschut 2013. The data do not provide evidence of gender differences in the need for such programmes, but teachers in the focus groups were certainly concerned that boys would use mobiles for sexual purposes. They were also concerned about the future for girls who became pregnant. The mobile phone may be viewed negatively by teachers as enabling greater independence for girls which is in turn linked to undesirable sexual behaviour leading to pregnancy (Porter et al. 2010).

\subsection{How do teachers and students perceive mobile phone use in relation to learning in rural Tanzanian secondary schools?}

Two things emerged consistently from the focus groups with students: First, students recognised the rule against bringing mobile phones to school. Second, most students used a mobile phone outside school. With primary school students and, to a lesser extent, the secondary school groups, the initial response to a question about their use was denial, followed by giggles when we asked "What, none of you?" But when we asked if they were able to save a message for their parents, or to send a text at their parents' request, most students relaxed and said they could.

Four things emerged from the focus groups with teachers. First, both schools banned students from bringing mobile phones to school. They justified the ban on grounds of disruption to lessons and the possibility of misuse, including cyber bullying. Second, we had a strong impression that teachers tended to underestimate the extent of students' use of mobiles outside school. It was apparent in the groups with students that a majority of group members, including in the primary schools, were familiar with mobile phones. Third, there was no recognition that government policy encouraged the use of mobile phones in learning. On the contrary, several teachers insisted that government policy forbade students from using mobile phones in school. Fourth, there appeared to be little discussion with students about safe and potentially positive uses of mobile phones. The only positive attitudes towards mobile phones (albeit frequently grudgingly expressed) were put forward by younger members of staff. Further study should be undertaken to explore whether there is a correlation between a teacher's attitude towards the potential value of mobile phones as educational tools and the age of the teacher.

\subsection{The potential for BYOD learning in rural Tanzanian schools}

The findings from this study bear out the assertion by Porter et al. (2016) that BYOD struggles to take hold due to relatively low levels of phone ownership (as opposed to casual access) among learners, compared to other areas of the world. The introduction of BYOD in these schools at present could be potentially socially divisive, opening up a digital divide between those learners whose parents could afford to furnish them with a device and those who were not so fortunate.

However, even if issues with device ownership can be surmounted (and given trends in ownership it is probable that this day will arrive in the foreseeable future), there are also deep rooted social factors which might inhibit BYOD learning. The teacher is crucial to the success of BYOD learning. Their sense of self-efficacy and disposition towards technology are important (Song and Kong 2017; Dennen and Hao 2014). 
Teachers in both schools overwhelmingly reported considerable scepticism that mobile phones would bring benefits to learning which would outweigh the erosion of moral values which they also believed was likely. Not only is this in line with previous work on parental and teacher attitudes to mobile phones in Tanzania (Kihwele and Bali 2013) or more widely across sub-Saharan Africa (Porter et al. 2016), it also mirrors the findings of BYOD research which highlights the risk of alienating parents from their children's learning by introducing unfamiliar pedagogic practices and making it too focused on small, personal screens (Parsons and Adhikar 2016). Ensuring the appropriate use of devices places as much responsibility on the teacher to embrace relevant (and more innovative) pedagogical practices (Farley et al. 2015; Cheng et al. 2016) as it does on learners to behave responsibly when using mobile phones for positive learning purposes.

\section{Conclusions}

The results of this study complement and enhance the conclusions reached by Kafyulilo (2014) that mobile phone use is both widespread among young people in Tanzania and that there are both potential educational opportunities as well as dangers associated with them. Mobile phone technology is readily available, costs little and has huge potential for use in teaching and learning. On the present evidence, however, that potential is far from being realised. For good reasons - the risk of disruption to lessons and the possibility of misuse - most teachers strongly resisted any suggestion that the ban currently in place could be replaced by use of mobile phones for educational purposes. They recognised the reality of cyberbullying and other abuses, but in common with past research, this study found no programmes implemented in schools for teaching student constructive uses of the technology (Porter et al. 2016; Kafyulilo 2014).

Whilst most teachers shared similar opinions in the focus groups, there were some positive voices speaking in favour of the potential use of phones. Theses tended to be younger, more junior teachers. Further study should be undertaken to explore whether there is a correlation between a teacher's attitude towards the potential value of mobile phones as educational tools and the age of the teacher. Future work should also include the training of participant-researchers to collect thematic story based interviews and interviews based on mobile call registers in an effort to compensate for the reticence of some participants to trust the anonymity of the questionnaire and focus groups (Porter et al. 2016).

The problem facing teachers is not principally their awareness of the risks inherent in students having access to mobile phones. More important, they need a framework that underpins the government's broad statement of support for use of new technology in learning. Such a framework would contain two elements. First, it would provide clear guidance on how to teach responsible use of mobile phone technology in the Tanzanian context. Second, this guidance would introduce a pedagogy that facilitated open discussion of the positive uses of mobile phones as well as the risks arising from their misuse. Currently, the almost automatic punishment for bringing a mobile phone to school ensures that educational discussion is shut down. Teachers urgently need resources that enable them to open up discussion. 
Acknowledgements The project was part-funded by a grant from the Wolfson Research Institute for Health and Wellbeing. As well as taking part in the research, Sebastian Kolowa Memorial University and Rock Memorial Education Trust provided invaluable advice and guidance throughout the project. We are grateful to the two necessarily anonymous local Districts for their permission to carry out the research and for their constant and constructive encouragement. We are similarly grateful to the head-teachers, staff and students for welcoming us to their schools. We are indebted to the staff of COCO for their assistance in translating the open-ended questionnaire responses.

Open Access This article is distributed under the terms of the Creative Commons Attribution 4.0 International License (http://creativecommons.org/licenses/by/4.0/), which permits unrestricted use, distribution, and reproduction in any medium, provided you give appropriate credit to the original author(s) and the source, provide a link to the Creative Commons license, and indicate if changes were made.

\section{References}

Adhikari, J., Mathrani, A., \& Parsons, D. (2016). Bring your own devices classroom: Issues of digital divides in teaching and learning contexts. Australasian Conference on Information Systems arXiv preprint arXiv: 1606.02488 .

Burton, P., \& Leoschut, L. (2013). School violence in South Africa: Results of the 2012 national school violence study. Cape Town: Centre for Justice and Crime Prevention.

Central Intelligence Agency (2017). Tanzania. In The world factbook. Retrieved from https://www.cia. gov/library/publications/the-world-factbook/geos/tz.html Last Accessed 30 Jan 2017.

Cheng, G., Guan, Y., \& Chau, J. (2016). An empirical study towards understanding user acceptance of bring your own device (BYOD) in higher education. Australasian Journal of Educational Technology, 32(4).

Cochrane, T., Antonczak, L., Keegan, H., \& Narayan, V. (2014). Riding the wave of BYOD: developing a framework for creative pedagogies. Research in Learning Technology, 22. doi:10.3402/rlt.v22.24637.

Dennen, V. P., \& Hao, S. (2014). Intentionally mobile pedagogy: the M-COPE framework for mobile learning in higher education. Technology, Pedagogy and Education, 23(3), 397-419. doi:10.1080/1475939 X.2014.943278.

Farley, H., Murphy, A., Johnson, C., Carter, B., Lane, M., Midgley, W., Hafeez-Baig, A., Dekeyser, S., Koronios, A. (2015). How do students use their mobile devices to support learning? a case study from an Australian Regional University. Journal of Interactive Media in Education. doi:10.5334/jime.ar.

Ford, M., \& Batchelor, J. (2007). From zero to hero-is the mobile phone a viable learning tool for Africa?. Proceedings of International Multi-Conference on Society, Cybernetics and Informatics: Vol. 2, (pp. 4753) SOIC 2007. Orlando, FL. 12-15 July, pp 7.

Galloway, D. M. \& Roland, E. (2004). Is the direct approach to reducing bullying always best?, in Bullying in schools: how successful can interventions be? Cambridge: Cambridge University Press, pp. 37-53. doi: $10.2277 / 0521821193$.

Gillies, C. G. M. (2016). To BYOD or not to BYOD: factors affecting academic acceptance of student mobile devices in the classroom. Research in Learning Technology, 24. doi: 10.3402/rlt.v24.30357.

Grimus, M., \& Ebner, M. (2014). Learning and teaching with mobile devices, an approach in secondary education in Ghana. In International Conference on Mobile Learning. S. 1.: IADIS Press.

Jones, B. H., Chin, A. G., \& Aiken, P. (2014). Risky business: Students and smartphones. TechTrends, 58(6), 73-83.

Kafyulilo, A. (2014). Access, use and perceptions of teachers and students towards mobile phones as a tool for teaching and learning in Tanzania. Education and Information Technologies, 19(1), 115-127. doi:10.1007 /s10639-012-9207-y.

Kumar, L. (2016). Bring your own device or bring your own distraction. International Journal of School and Cognitive Psychology. doi:10.4172/2469-9837.1000170.

Kamau, L. M. (2014). Technology adoption in secondary mathematics teaching in Kenya: An explanatory mixed methods study.

Kasumuni, L. (2011). Delivering video by mobile phone to classrooms in Tanzania. Retrieved from http://elanewsportal.com/delivering-video-by-mobile-phone-to-classrooms-in-tanzania/.Last Accessed 19 Jan 2017. 
Khaddage, F., Müller, W., \& Flintoff, K. (2016). Advancing mobile learning in formal and informal settings via mobile app technology: where to from here, and how? Educational Technology \& Society, 19(3), 16-27.

Kiger, D., \& Herro, D. (2015). Bring your own device: Parental guidance (PG) suggested. TechTrends, 59(5), 51-61.

Kihwele, E. J., \& Bali, A. L. T. (2013). The perceptions of teachers, parents and students on the effects of Mobile phone use on student learning in Tanzania. Journal of Education and Practice, 4(25), 101-106.

Machuve, D., Zlotnikova, I., \& Nyambo, D. (2014). Monitoring and evaluation of the e-readers project in rural Tanzania. In Science, computing and telecommunications (PACT) (pp. 62-67). Arusha: IEEE. doi:10.1109/SCAT.2014.7055138.

Ministry of Education and Vocational Training (2007) ICT policy for basic education.

Ministry of Education and Vocational Training (2010). Secondary education development programme II (Final Draft).

Mtebe, J. S., \& Kissaka, C. (2015). Students' experiences and challenges of blended learning at the University of Dar es Salaam, Tanzania. International Journal of Education and Development Using Information and Communication Technology, 9(3), 124.

Murugesan, S. (2008). Harnessing green IT: Principles and practices. IT Professional, 10(1), 24-33.

Ovejero, A., Yubero, S., Larrañaga, E., \& Moral, M. D. L. V. (2016). Cyberbullying: Definitions and facts from a psychosocial perspective. In Navarro, R., Yubero, S., Larrañaga (Eds.), Cyberbullying Across the Globe (pp. 1-31). Springer International Publishing.

Parsons, D., \& Adhikar, J. (2016). Bring your own device to secondary school: The perceptions of teachers, students and parents. Electronic Journal of e-Learning, 14(1), 66-80.

Porter, G., Hampshire, K., Abane, A., Robson, E., Munthali, A., Mashiri, M., \& Tanle, A. (2010). Moving young lives: Mobility, immobility and inter-generational tensions in urban Africa. Geoforum, 41(5), 796804. doi:10.1016/j.geoforum.2010.05.001.

Porter, G., Hampshire, K., Abane, A., Munthali, A., Robson, E., Mashiri, M., \& Tanle, A. (2012). Youth, mobility and mobile phones in Africa: findings from a three-country study. Information Technology for Development, 18(2), 145-162. doi:10.1080/02681102.2011.643210.

Porter, G., Hampshire, K., Milner, J., Munthali, A., Robson, E., de Lannoy, A., ... \& Abane, A. (2016). Mobile phones and education in Sub-Saharan Africa: From youth practice to public policy: Mobile phones and education in Africa. Journal of International Development, 28(1), 22-39. doi:10.1002 jjid.3116.

Song, Y., \& Kong, S. C. (2017). Affordances and constraints of BYOD (Bring Your Own Device) for learning and teaching in higher education: Teachers' perspectives. The Internet and Higher Education, 32, 39-46. doi:10.1016/j.iheduc.2016.08.004.

Swarts, P., \& Wachira, E. (2010). Tanzania: ICT in education situational analysis. (Global e-Schools and Communities Initiative,) (pp. 20-33).

Traxler, J. (2016). Inclusion in an age of mobility. Research in Learning Technology, 24. doi:10.3402/rlt. v24.31372

Traxler, \& Kukulska-Julme, A. (2005). Mobile learning in developing countries. (The Knowledge Series) (p. 6). Vancouver: Commonwealth of Learning.

UNICEF/Intermedia (2013). A (Private) Public space: Examining the use and impact of digital and social media among adolescents in Kenya/Available from http://www.intermedia.org/a-private-public-spaceexamining-the-use-and-impact-of-digital-and-social-media-among-adolescents-in-kenya/. Last Accessed 13 Sep 2016.

United Republic of Tanzania (1999). The Tanzania Development Vision 2025

Zlotnikova, I., \& van der Weide, T. (2015). Community outreach projects as a sustainable way of introducing information technology in developing countries. International Journal of Education and Development Using Information and Communication Technology, 11(1), 55. 